\title{
The Chinese Script in the Chinese Scriptworld
}

\section{Chinese Characters in Native and Borrowed Traditions}

\author{
Edward McDonald \\ Sun Yat-Sen University \\ mcdonald3@mail.sysu.edu.cn
}

\begin{abstract}
The exclusivist ideology characterizing the Chinese writing system as "ideographs" was constructed in the West, and later reimported into China where it influenced popular and nationalistic understandings of the characters. For the West, the Chinese script held out the promise, embraced particularly eagerly by the literary and artistic worlds, of a visual language not complicated by questions of sound, and thus by the arbitrary impositions of individual languages (Bush). For China, the Chinese script came to function as one of the key cultural characteristics marking the Chinese off from the rest of the world (Shen). This paper will attempt to provide some conceptual groundwork for understanding these complex and overlapping discourses, and set out the fundamental graphological basis through which the differing functions of Chinese characters in both the historical and the contemporary Chinese Scriptworld (Handel) can be understood.
\end{abstract}

\section{Keywords}

Chinese characters - ideograph - graphological - linguistic sign

\section{Orientation}

Cultural evolution is multi-dimensional and unpredictable. Cultural practices, like material objects, can be passed on from culture to culture and take on completely new meanings in new contexts. The modern academy tends to valorize this process as one of "hybridity", but whether this should be celebrated as a good in itself, or to what extent the competing pull of native and borrowing cultures should be acknowledged, is perhaps still problematic. The script 
known in English as "Chinese characters" proclaims in its very name its status as a cross-cultural product. Like the many foodstuffs in Chinese prefixed with terms indicating their foreign origin, such as the humble tomato, whose original Nahuatl name tomatl was imported barely changed into English, but which turns up in Chinese as either "Western red persimmon" xihongshi 西紅 柿 or “foreign eggplant” fanqie 番茄, Chinese characters as they are understood today in both China and the West are the joint creation of a number of competing discourses over several centuries, borrowed from one culture into another, and then borrowed back more or less transformed.

In the West, the discipline of sinology, in effect a branch of philology as applied to Chinese texts, developed from the eighteenth century predicated on the mastery of Chinese characters (Honey). In the second half of the twentieth century, this content-based and methodologically-defined area of study began to give way to a new multi-disciplinary field of Chinese Studies, which nevertheless continued to stress the importance of dealing directly with Chinese texts and hence with Chinese characters (McDonald "Ideolatry"). The discipline of linguistics, however, as it took shape from the late nineteenth to early twentieth centuries, did not coexist comfortably with either the old or the new of these dispensations, as it struggled to free the study of language from its traditional focus on the written word, and for much of the 2oth century was relatively uninterested in writing systems except as more or less efficient representations of sound (DeFrancis "Ideographic"). At the same time, in providing a "scientific" vantage point on both Chinese characters and traditional Chinese understandings of language, linguistics competed with more "humanistic" approaches within Chinese Studies for authority over language and writing (Lurie).

During this same period in the West, Chinese characters had to some extent escaped from the experts to become part of the wider scholarly landscape, with philosophers of the stature of Francis Bacon, Wilkins, and Leibniz incorporating them, often in misunderstood or only partially understood versions, into their own philosophical and ideological projects (Porter). At the beginning of the 2oth century, the unlikely combination of a deceased Japanologist and an avant garde poet gave the characters a putative new role as a visual language released from the mediation of sound, and therefore with a direct link to the materiality and agency of the natural world (Fenollosa \& Pound). This (purely) visual understanding of the characters, never a significant feature of the native Chinese linguistic tradition, was perhaps reinforced by the discovery in the late 19th century of the earliest forms of the characters in the jiaguwen 甲骨文 or "oracle bone texts" in which the characters' pictorial origins were more obvious, and then fed back into Chinese Studies, in an effective scholarly line of succes- 
sion from Creel et al. (Literary) to Rosemont Jr. ("On Representing"), Hansen (Language, Writing) and Ames \& Rosemont Jr (Analects).

In dealing with this complex of competing discourses from a broadly graphological point of view, rather than attempt to lay down an "argument" as to "correct" or "incorrect" understandings of Chinese characters, I have chosen rather to lay out a "narrative" of some of the key "themes" that can provide insights into the forms these discourses have taken over the years. It is for this reason that the individual sections of the paper are named according to the stages in Labov \& Waletzky's famous model of the narrative ("Narrative"), which came out of linguistics but has been found useful by many outside that discipline, a fate I may hopefully envisage for the current paper. This aim also explains a perhaps rather more "literary" cast to the language of the present text than might be expected in a paper of this kind.

\section{Complication}

Controversies such as the so-called "Creel-Boodberg debate" (Creel; Boodberg; McDonald "Ideolatry"), or the cross-generational critiques of Ezra Pound (Kennedy; Yip) provide some insights into the complexity of the cross-cultural influences involved in understandings of Chinese characters, the competing ideological and disciplinary complexes at play, and the sheer possibility of misconstrual and misunderstanding across different schools of thought. But it is perhaps worthwhile putting the question: does this really matter? If Creel and Pound got Chinese characters "wrong," as Boodberg and Kennedy and Yip argue very forcefully that they did, wasn't this error a very fruitful one which has had highly creative effects in their respective fields? Aren't the sinologists or the linguists simply attempting to play the role of prescriptive gatekeepers of knowledge, reinforcing the purity of their own boundaries and cramping the free growth of ideas?

As I explained earlier, it is not the aim of this paper to pronounce on these issues; and as a linguist myself, I might fall under suspicion of having, as our publishers commonly require us to state these days, "competing interests". But what I will say is that many of those arguing for, as it were, a "free trade agreement" across cultural borders often want to have it both ways. Pound, for example, was not only drawing on Chinese characters as a model for his theory and practice of Vorticist poetry, whose foreign origins-like, it seems, the Sanskrit origins of Chinese "recent style verse" jintishi 近體詩 or "regulated verse" lüshi 律詩 (Mair \& Mei; Klein)—could be regarded simply as a jumping-off point; he was also drawing on the cultural authority of the "China" which had held such 
a key role in the European imagination since at least the 16th century; even if he was putting forward a much more materialist interpretation of the characters than the idealist ones more common before his time. So when he famously translated the opening of The Analects as "study with the seasons winging past", based on a quite ill-informed confusion of the graphic and the lexical in written Chinese relating to the word $x i$ "practice," whose character 習 does indeed have two "feathers" perched on top, he was making an interpretation which may have appealed to many of his English readers as exotically Chinese; but which would have struck any Chinese readers as nonsensical, particularly given the characteristically Confucian linking of "study" and "practice" emphasised in the original Old Chinese saying: xue er shixi zhi 學而時習之 “to study and in a timely fashion put into practice."

\section{Resolution}

So, in laying out, rather than laying down, these conceptual foundations for an understanding of the Chinese script at the heart of the Chinese Scriptworld, I am not arguing for anything like a monolithic interpretation of Chinese writing. The literary practitioners and theorists and the philosophers and the archeologists and the linguists will all quite rightly have their own "takes", and I am in no way putting forward exclusive claims for any one of these groups. What I am arguing is for communication between the different groups; and an informed understanding of all of the practices associated with the Chinese script, practices which in their different ways help to define what kind of complex cultural object the script is. I will, however, insist that what we are dealing with here is a script, and thus something ultimately meaningful only in relation to a particular language or variety of a language (see the discussion of "meaning" versus "idea" below). I will also point out that it was the nature of what is variously called Old Chinese or Archaic Chinese or Shanggu Hanyu 上古漢語 as a largely "monosyllabic" language that determined the fundamental feature of the script whereby each character represented a syllabic-morpheme. This feature of the script shows up very clearly when it was borrowed to represent its neighbouring languages of Vietnamese, Korean, and Japanese, where the characters were used to represent either syllabic-morpheme combinations, or separately syllables or morphemes. (All these terms will be explained below.) What I am recommending, in sum, is a version of British linguist J.R. Firth's call for "renewal of connection" between theory and data; or perhaps in a broader sense, in line with our collective responsibility as scholars, stressing the message of Firth's literary contemporary E.M. Forster, "only connect". 
So I will be emphasizing here a number of key characteristics of hanzi 漢字 that I believe need to be at least acknowledged in any discussion of the characters, in whatever area of application. These characteristics are graphological in the first instance, and more broadly, linguistic. To put my own convictions on display from the outset, I do not believe that a cogent case has been put forward for Chinese characters as somehow representing a purely visual writing system, particularly in relation to the traditional written standard Literary or Classical Chinese (Creel; Rosemont Jr); nor do I accept, regardless of Derrida's broader philosophical aims, that Chinese characters can be used as some kind of evidentiary base for proposing a new kind of disciplinary approach to language in the form of "grammatology" (Derrida). I do, however, recognize that Chinese characters, like writing systems in most literate cultures, have become the repository of much cultural value, and have therefore given rise to a great deal of "myth-making" which often credits them with more value or capabilities than they can actually bear. My account will thus leave itself open to differing possibilities, but insist on an ultimately graphological connection to all interpretations.

Many accounts of Chinese writing (e.g. Zuo, xii) draw a misleading dichotomy between two types of writing systems: on the one hand, "semantic," Chinese biaoyi 表意 "expressing meaning," such as Chinese characters; and on the other "phonetic," Chinese biaoyin 标音 "notating sound," as with alphabetic writing systems. In fact, as the same author earlier states, all writing systems represent “vocal language” yousheng yuyan 有聲語言: where sheng 聲, like its almost exact equivalent in Latin vox "voice" from which our term "vocal" is derived, refers to "meaningful sound." It may therefore be more useful to think of the ultimate goal of all writing systems being to represent wording, in the sense of meaningful combinations of sound, rather than sound per se, as has been the tendency in many linguistic accounts of writing systems in the Chinese Scriptworld (e.g., DeFrancis Visible; Hannas).

As recognized by Saussure in his notion of the "linguistic sign," wording is that quintessentially linguistic phenomenon whereby stretches of sound are mutually delimited with stretches of meaning (Saussure Cours). Wording is the meat at the heart of the linguistic sandwich, it is the daily currency of ordinary speakers, it is what readers grapple with in interpreting the graphic symbols of writing, as well as what professional writers and editors worry over ("I'm not sure about the wording of this paragraph"). But Saussure's linkage of meaning and sound in the linguistic sign, as reflected in the distinction between signified and signifier, goes further than is normally understood, in showing that linguistic meaning cannot exist without sound, or vice versa: as combined in units of wording, the two are reciprocally defining. If sound is not linked 
to meaning, as when we hear a language we do not understand, it becomes merely noise. As for the opposite linkage, that between meaning and sound, it is important to distinguish between meanings, which are necessarily linked to sounds, and ideas, which need not be. This is not merely for some reason of definitional convenience, but because what are represented by writing systems are precisely meanings, not ideas. This explains the long-running objection of linguists within Chinese Studies to the use of the term ideograph, literally "written (representation of) idea," since it elides the crucial contribution of sound to the linguistic sign; and their recommendation of terms such as logograph "written (representation of) word" as a more accurate alternative (du Ponceau; Lurie).

In the current context, moreover, if we characterize all writing systems as "expressing wording," Chinese biaoci 表辭, then this has the happy effect of putting them on a level playing field from the start. Differences then emerge when a writing system evolves, or is devised for a particular language, as to which of the number of possibilities is chosen in how it represents wording. Halliday represents these options very clearly in the figure below (reproduced from Halliday Spoken, Fig. 3.2: 43).

The individual written symbols of a writing system, technically known as its graphs, may represent units of wording themselves, in the form of words or their constituent parts, morphemes: historically, this seems to have been the initial option for all the originally devised writing systems known or so far deciphered, such as Sumerian cuneiform, Egyptian hieroglyphs, Mayan glyphs, and of course Chinese characters (Boltz, Ch. 3). Often the next development for a writing system is to represent the minimally pronounceable units of sound, syllables. Syllables are the counting units of language, they - are - what - we fall - back - on - when - we - need - to - as - it - were - ex-pec-to-rate our message. A possible next stage is to "reduce" each syllable to its minimal component parts, mostly not pronounceable in isolation and therefore more "counterintuitive" in that sense. Historically this development only took place once, in the particular historical context of the Semitic languages: firstly by representing only the consonants of each syllable, nd lvng $t$ th vwls, a procedure which works efficiently only for certain kinds of languages; and then when the Greeks took over one Semitic alphabet, by "reinserting" the vowels, t-o p-u-t a-ll th-e s-ou-n-d u-n-i-t-s o-n d-i-s-p-l-ay.

The above "sequence" does not represent any sort of inevitable historical development, though again all the writing systems to which we have access went through at least the first two or three stages. The reasons why writing systems evolve more often have to do with them being adapted to other languages which they don't fit quite as well as their original language than for any reasons 


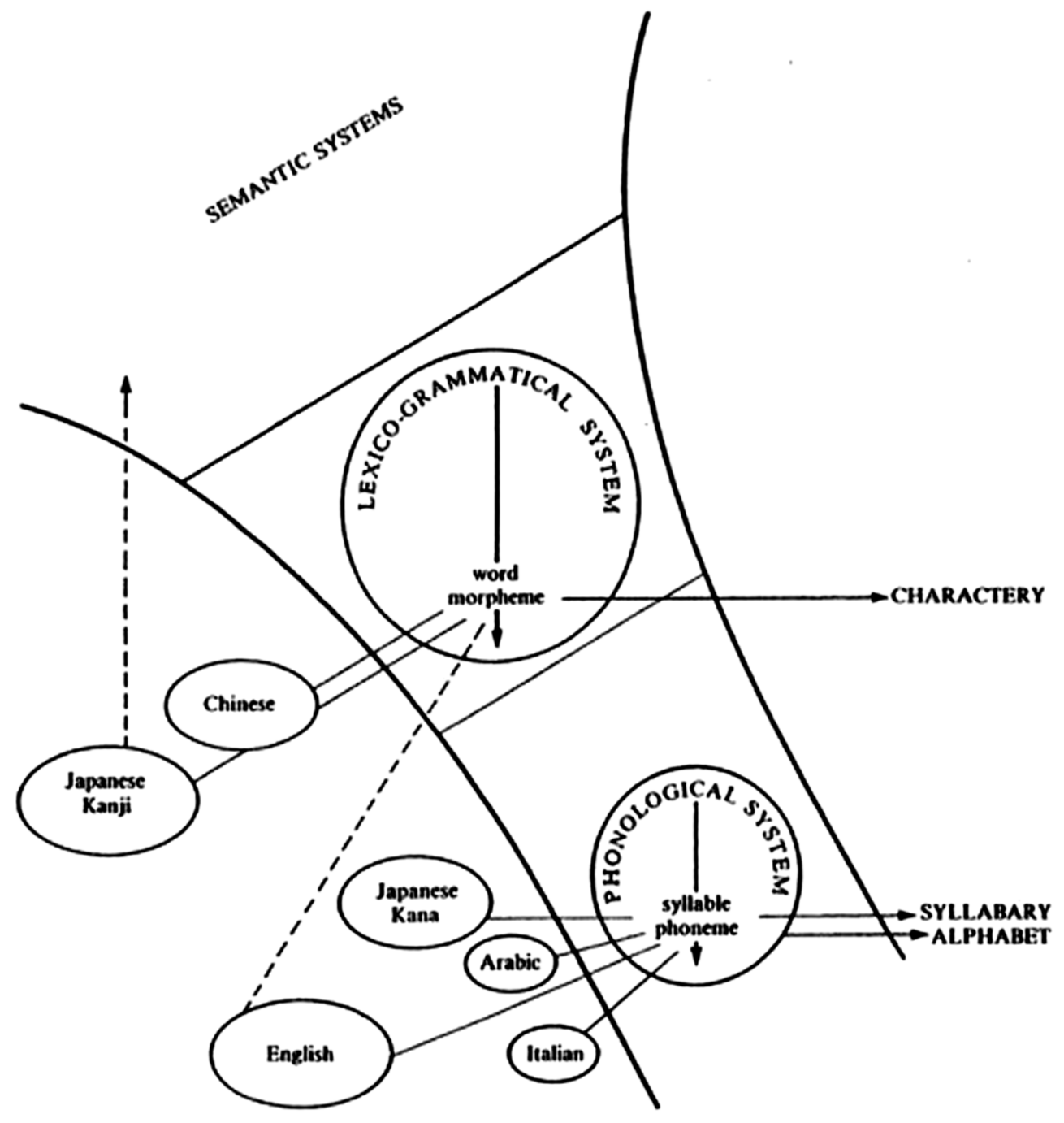

FIGURE 1 How writing systems represent language

of "efficiency". The users of writing systems are notoriously reluctant to change them even when the original language has changed radically: we need only mention the case of the English writing system, which still pretty well matches the spoken language of Chaucer's day (i.e., c. $1400 \mathrm{CE}$ ). I should also stress that the above represents an ideal schema, and many writing systems draw on more than one kind of system to represent the wordings of their languages: in the context of the Chinese Scriptworld, Japanese is the classic example of a mixed system. It is also important to stress, particularly in the light of claims that 
Chinese characters represent some sort of supralingual means of communication, that all four polities historically part of the Chinese Scriptworld-China, Vietnam, Korea, Japan - have in the past been joined by the common use in education, literature, and diplomacy of not just Chinese characters but also Chinese language: so-called Literary Chinese or Classical Chinese-in Chinese wenyan 文言. This standardized syncretic form of Old Chinese started to take shape from the beginning of the Imperial period in around $200 \mathrm{BC}$, and was of course written in Chinese characters.

The Chinese character writing system, which as far as we know was a local development, was fundamentally shaped by the nature of the language it set out to represent, as is inevitably the case with any writing system. As already noted above, a prominent feature of the earliest forms of Chinese known to us is an almost complete identity between the minimal unit of wording, in the Chinese case the word, and the minimal unit of sound, in the Chinese case the syllable (Boodberg): that is to say, the huge majority of words were a single syllable long, and therefore the minimal unit of writing, the character, could represent both at the same time. So when a reader read (out) a text, they would simultaneously be sounding the syllables and articulating the words of the text. This forms the basis of the reading practices associated with Classical Chinese, although these practices become more complex as the writing system is carried over to Modern Chinese, where the one syllable-one word principle is hugely diluted, and where one of the main challenges is hence working out where the word boundaries are.

In terms of devising individual characters to represent each syllable/word, there were two basic options, and a third which was a combination and a later historical development of the two: represent the meaning, using a semantograph; represent the sound, using a phonograph; and represent both sound and meaning, using a semanto-phonograph. In this case, however, this does seem to have involved an evolutionary trajectory. Although in the earliest texts to which we have access, the writing system is already more or less fully developed, it seems clear that the semantographs came first, in the form of, to use renderings of the traditional terms, concrete pictographs (xiangxing 象形 “imitating shape,") abstract pictographs (zhishi 指事 “referring to events,") and composite semantographs (huiyi 會意 "combining meanings"). At this point, however, we need to reiterate our mantra: writing systems fundamentally represent wording. Given that wording is defined as meaning + sound, this means that semantographs can only represent meaning as attached to sound. So although the formation of these graphs was on semantic principles, the fact that they were graphs meant that in usage in actual texts they were attached to specific words with particular pronunciations in Old Chinese. 
One of the main pieces of evidence for this is that, in the earliest texts, many of these semantographs assume a derived function as phonographs: that is, they are used to represent other words which have the same or similar sound as the original word for which the character was devised. This is known in graphology as the rebus principle, and is again a feature of all original writing systems: it is often seen as the point when conceptually for its devisers the writing system comes to be understood as representing wordings rather than things or notions. In the case of Chinese, many of the grammatical words of Old Chinese are represented by such phonographs, known traditionally as “borrowings" jiajie 假借: for example, zhi 之 "go" was borrowed in this way to represent the 3 rd person pronoun $z h i$ 之, with both original and borrowed usages continuing to exist side by side.

In other cases, the character came to be exclusively attached to the borrowed usage, and a new character was devised for the original by adding an extra semantic element: for example, the character 其 for $j i$ "winnowing basket" was borrowed to represent $q i$ "possessive pronoun" and a new character was devised for $j i$ by adding the semantic element 竹 $z h u$ "bamboo" on top-thus 箕. This third kind of character, the semanto-phonograph, or xingsheng 形聲 "form and sound" proved to be the most efficient way of devising new characters, and is now by far and away the most common type, at about $90 \%$ of existing characters. In some cases, phonographs and / or semanto-phonographs continued to be exchangeable across a range of similar sounding characters, and this multiple usage long remained a feature of the written language, for example, the second half of the Confucian saying (mis)translated by Ezra Pound above runs bu yi yue hu 不亦說乎 “is this not a pleasure?" with the third character shuo 說 "explain" "read as" yue 悅 "please."

As explained in Handel and covered in more detail in other papers in this special issue, when the Chinese script was borrowed to represent other languages in what we might call the "Chinese Character Region" or Hanzi Diyu 漢字地域, the characters were borrowed either for their meaning or for their sound, or both. The final possibility meant that in effect the whole word was borrowed, as adapted to the sound system of the borrowing language: these are the so-called onyomi 音讀 or "sound readings" of Japanese such as san 山 "mountain," corresponding to modern Mandarin shan. The extensive SinoVietnamese, Sino-Korean, and Sino-Japanese vocabulary in these three languages provides good evidence of this phenomenon, as can be seen from the names of the three respective countries, which have a distinctly Sinocentric flavour: 越南 Vietnam / Yuenan "Beyond the South," 朝鮮 Chosun / Chaoxian "Morning Calm," 日本 Nippon / Riben "Source of the Sun." 
The second possibility was basically an extension of the jiajie "borrowing" technique already widely used in Chinese texts: this was probably the earliest strategy used to represent native words; and its present day descendant is the Japanese kana 假名, whose title "borrowed names" references the Chinese category, whose shapes are simplified or partial versions of particular Chinese characters, and whose syllables - again following the Chinese model in taking this as the basic sound unit - are Japanised versions of the original Sino-Japanese words. The first strategy can be seen in the so-called kunyomi 訓讀 or "interpretation readings" of Japanese, where the Chinese character is matched to a synonymous native Japanese word, such as yama 山 mountain.

In the modern period, while Japan held on to a mixed script of characters (kanji) and syllabic graphs (kana), both Vietnam and Korea took new routes in adopting for their languages writing systems which have little or no connection with Chinese characters. Nevertheless, in the pre-modern period, both had developed writing systems very closely based on the Chinese script and the logic of its formation and use, so that again, the borrowing / adaptation was always one of either meaning or sound, never of what Boodberg called a "disembodied word" (332 n. 5). The reading practices associated with Chinese character texts across the Chinese Scriptworld would have driven home the fact that each character had one or more readings: there was thus never any basis for the misinterpretation later made by European scholars that the characters were purely visual signs without attached words. Hence any transfer via Chinese characters was always made from the wordings of one language to the wordings of another: there was no superlingual realm of "ideas" through which such a transfer might be effected:

In either case, the transfer was made from a word or word element in one language to a word or word element in the other: at no stage did the process take place directly through ideas.

MCDONALD, "Getting” 1200, original emphasis

\section{Evaluation}

The "problem" of the Chinese writing system, by some quirk of history or typology, touches on two of the areas in which modern linguistics has been most deficient: writing, and meaning. As the brief account above should suggest, the whole topic of writing systems is much more complex than it has been given credit for, either within linguistics, or across the range of other disciplines and fields which have shown an interest in Chinese characters. If I might take the lead in being critical of my own discipline, I would suggest that one of 
the reasons for this is not so much a supposed "phonocentric" bias that sees the written form as derived and therefore secondary (Derrida), but rather a reluctance to deal directly with the issue of meaning, and therefore an incomplete understanding of the function of writing systems as representing the combination of meaning and sound that is embodied in wording rather than simply representing sound. This reluctance, characteristic of Leonard Bloomfield and the traditions in North American linguistics influenced by him (but not those stemming from Edward Sapir, or for the majority of European traditions such as the Prague, Copenhagen, or London schools among others), can be seen as an inability, for whatever reason, to follow through the implications of the conceptualisation of meaning put forward by the putative Father of Modern Linguistics, Ferdinand de Saussure.

Saussure was insistent that the word as linguistic sign must incorporate both meaning and sound, and if either was looked at isolation, it ceased to be of linguistic significance:

The one a priori truth whose validity rests on simple common sense is that while there may be psychological facts, and while there may be phonological facts, neither of the two series alone would ever be capable of giving rise to any linguistic fact whatsoever. For there to be a linguistic fact, the two series must exist in union.

SAUSSURE, Écrits 68, original emphasis

The same logic applies when we add graphological facts to this mixture. Any Chinese character, therefore, exists meaningfully only as part of a whole complex of meaning-sound-graph: in Boodberg's terms, semanteme-phonemegraph, a connection which must be established through convention.

The habitual association of a graph (G) with the corresponding semanteme and phoneme (SP) which culminates in the apprehension of the graph by the reader of the language of which it forms an element as a single complex GSP can be achieved only through a long usage of the language and the particular graph and only after conventions have been firmly established.

BOODBERG $33^{2}$

The importance of convention was maintained when Chinese characters were borrowed into the neighbouring cultures of the Chinese Scriptworld. Unlike an alphabetic script, whose graphs come attached to individual sounds of a language, and can therefore be "detached" relatively easily to be applied to the 
sounds of another language, Chinese characters came attached to wordings, which are more resistant to being "detached" in this way, although the sounds may be adapted to the phonology of the borrowing language to give what we might loosely think of as an "accent". For example, to this day the Chan 禪 Buddhist writings taken over for use in Japanese Zen 禪 Buddhist rituals are read aloud using the Sino-Japanese pronunciations of the characters, giving a "language" which aurally is neither Chinese nor Japanese; but which, nevertheless, as a kind of oral equivalent of the character text, still maintains the essential S-P-G links of the original. A similar phenomenon may be seen in Cantonese pop songs, whose lyrics are in standard written Chinese, i.e. Mandarin, but pronounced according to their Cantonese "readings", including not only the lexical words, which are often cognate in Mandarin and Cantonese and thus represented by the same characters, but also the grammatical words which are more often than not different between the two. So when a crooner complains in Mandarin “he doesn't love me” 他不愛我 ta bu ai wo, we get a Cantonese reading ta bat ngoingo, which is quite distinct from its genuine Cantonese equivalent 佢 唔仲意我 koeim zungjingo.

It is worthwhile stressing the importance of the inextricably linguistic process of the transmission of Chinese characters - or in reality, the transmission of Chinese texts, i.e. for most of the historical period, texts written in Literary Chinese using Chinese characters, across the Chinese Scriptworld. Related to this is the crucial distinction, already mentioned above, between "ideas", which are not necessarily linguistic, and "meanings" which must be. Since this is a topic for which Saussure has hitherto provided the most cogent explanation, we should briefly revisit it.

Saussure's model of the linguistic sign as a combination of mutually defining concept or signified and sound or signifier does not posit "meanings" as some sort of "semantic primes" which lie behind all language use and are stored in some form in the brain. Such an older conception of meaning goes back in the Western tradition to Aristotle's notion of "ideas" existing in the mind which are "likenesses" of events in the world and which may be "symbolized" by spoken or written words. Instead Saussure's model recognizes "wordings", each of which consists of a stretch of meaning mutually delimited with a stretch of sound. In other words, meanings are not simple elements in the form of psychological "objects" like Aristotle's "likenesses", but rather relations between two very disparate human faculties, the brain which makes sense of our experience and the vocal tract which provides one way of expressing our feelings and thoughts:

A linguistic entity is unique in that it involves the association of two distinct elements. If we were invited first to determine the chemical 
classification of a sheet of iron, gold, or copper, and then the zoological species of a horse, cow, or sheep, these would be two easy tasks. But if we were asked to determine what "species" is represented by the odd combination of an iron plaque attached to a horse, a gold plate on a cow, or a sheep adorned with something copper, we would exclaim that the task was absurd. The linguist has to realize that it is precisely this absurd task that faces him right from the very outset.

SAUSSURE, Écrits 3, original emphasis

The kind of relational thinking proposed by Saussure goes against the atomistic reductivist approach to complexity characteristic of Western thinking since the time of the ancient Greeks; though interestingly it seems much more consonant with the correlative style of thinking characteristic of ancient Chinese thinkers.

The two main implications of this model is that meanings cannot be either "disembodied", or "natural". So on the one hand, if there are no such things as "ideas without expressions" or "meanings without sounds" (sign languages are exactly comparable to spoken languages in this sense, merely replacing sound with gesture), then the only way these two separate regions can be brought together is through social interaction:

Language is always being considered within the human individual, a false viewpoint. Nature gives us man ready made for articulated language, but not actually in possession of it. The language system is a social fact. The individual, organized with a view to speaking, may only use the vocal apparatus in the context of his community-moreover, the individual only feels the need to use it when interacting with that community.

SAUSSURE, Écrits 120, original emphasis

On the other hand, rather than language merely taking on a labelling or recording role in relation to reality, each language takes an active role in dividing up the continuum of reality in ways that are functional for its speakers, with particular wordings being only "negatively" distinguished from other wordings; and hence meanings or ideas also share this fundamentally negative, contrastive quality.

It is fundamental that a word may only approach a material object through an idea which is both quite insufficient when taken in relation to the object, and boundlessly vast when taken outside the object (it is always too wide and not comprehensive enough to use ...). This idea being 
fundamentally negative, the "literal" meaning becomes merely one of the manifold manifestations of the general meaning. This general meaning is simply a fortuitous boundary born of the simultaneous presence of other items.

SAUSSURE, Écrits 55

\section{Coda}

To finish up by drawing out the implications of our "narrative", how is all this relevant to the Chinese Scriptworld? Well, just as in crime stories the detective is encouraged to "go for the money" in trying to solve a crime, I would recommend all scholars working on Chinese characters to "go for the meaning" in trying to understand how characters work. Historically speaking, while acknowledging the persistent conceptualization of Chinese characters in European scholarship and culture as what Bacon called "characters real," "which express neither letters nor words in gross, but things or notions," more commonly known in the last two centuries as "ideographs," we cannot deny that for all traditions where Chinese characters were in active use as a writing system, whether for one or other varieties of Chinese or for the neighbouring languages of Vietnamese, Korean or Japanese, they did in fact express either "letters" (in pre-modern European usage equivalent to "sounds" and thus in a Chinese context comparable to "syllables") or "words," not "things or notions."

We must also admit that understandings of the characters in the Chinese tradition are quite different to their Western appropriations, particularly in relation to the so-called "pictographic" nature of characters, something which was never accorded particular attention by pre-modern Chinese scholars. But theoretically speaking, I believe we must also face up to the fact that for no language or writing system is there any plausible mechanism whereby "ideas" can exist without wordings to express them, and so the notion of "ideograph" in this context is both practically unworkable and theoretically incoherent. You will note that I specify "for no language or writing system." I am obviously not denying the possibility of being able to express "ideas" visually without involving the medium of sound. But the whole point about Chinese characters, like other supposedly "pictographic" writing systems like Egyptian hieroglyphs, is that they are not pictures, let alone graphic shapes which somehow correspond directly to ideas: they belong to writing systems and hence represent wordings, i.e. combinations of meaning and sound.

Around the middle of the last century, there was a fashion for so-called "inductive" methods of learning Chinese characters as demonstrated in a popu- 
lar series of textbooks of Classical Chinese (Creel et al.) which aimed to uncover the "graphic logic" of characters. These kinds of "inductive" interpretations of characters that have been such a feature of sinological and popular discourse since at least Creel's time are completely misnamed. They are not in fact inductive but deductive: they work backwards from the meaning of the relevant word in order to explain the formation of the character. A truly inductive interpretation of Chinese characters, one that treated them as purely graphic forms, would be a completely unconstrained one, generating a plethora of possible interpretations with no way of working out which was the correct one. So if we "go for the meaning," we still need to "go for the wording," and that involves the particular linkage of meaning and sound provided by a particular language or variety of a language.

The dream of the "ideograph," the "universal character," the symbolic system which could represent "reality" directly, without needing to go through any particular and partial language, has indeed been a beautiful dream, but it seems to me it is time to wake up. It is time to acknowledge the native contexts and traditions of Chinese characters, and while not discounting the historical significance of their borrowings into other traditions, to admit that when all is said and done, what we are dealing with is a writing system. This writing system has not only inspired the fantasies of generations of philosophers and writers, it has also presented a severe challenge to the biases of an alphabetic-derived tradition of linguistics. It is now time for scholars to set an example by recognizing the nature of reading practices on both sides of the complex processes of cultural borrowing, to admit that when it comes down to it writing systems across the whole Eurasian continent share more similarities than differences, and to give up the hope, once and for all, that any one side can claim some sort of exclusivity or incommensurability when it comes to cultural production.

\section{Works Cited}

Ames Roger T. \& Henry Rosemont, Jr. The Analects of Confucius: A Philosophical Translation, New York: Ballantine Books, 1999.

Bacon, Francis. The Advancement of Learning. 1605. Renascence Editions: An Online Repository of Works Printed in English Between the Years 1477 and 1799. Web. 10 March 2016.

Boltz, William G. The Origin and Early Development of the Chinese Writing System. New Haven ст: American Oriental Society, 1994.

Boodberg, Peter A. "Some Proleptical Remarks on the Evolution of Archaic Chinese." Harvard Journal of Asian Studies 2 (1937), 329-372. 
Bottéro, Françoise. "Revisiting the wén 文 and the $z i$ 字: The Great Chinese Characters Hoax." Bulletin of the Museum of Far Eastern Antiquities 74 (2002), 14-33

Bush, Christopher. Ideographic Modernism: China, Writing, Media. Oxford: Oxford up, 2010

Creel, Herrlee Glessner. “On the Nature of Chinese Ideography." T'oung Pao 32 (1936), 85-161.

Creel, Herrlee Glessner, Chang Tsung Ch'ien, and Richard C. Rudolph. Literary Chinese by the Inductive Method, vols 1-3. Chicago IL: University of Chicago Press, 1938$195^{2}$.

DeFrancis, John. Visible Speech: The Diverse Oneness of Writing Systems. University of Hawaii Press, 1989.

DeFrancis, John. “The Ideographic Myth." In Difficult Characters: Interdisciplinary Studies of Chinese and Japanese Writing, ed. Mary S. Erbaugh, Ohio State University: National East Asian Languages Resource Center, 2002, 1-20. Pathways to Advanced Skills. 6.

Derrida, Jacques. De la grammatologie. Paris: Les Éditions de Minuit, 1967. Trans. Gayatri Chakravorty Spivak. OfGrammatology. Baltimore \& London: Johns Hopkins UP, 1974.

Du Ponceau, Peter S. "A Dissertation on the Nature and Character of the Chinese System of Writing." Transactions of the Historical and Literary Committee of the American Philosophical Society vol. 2 (1838).

Fenollosa, Ernest \& Ezra Pound. The Chinese Written Character as a Medium for Poetry. Originally published in Instigations, London, 1920. Reprinted 1936. San Francisco: City Lights. Fenollosa, Ernest \& Ezra Pound, ed. Haun Saussy, Jonathan Stalling, and Lucas Klein. The Chinese Written Character as a Medium for Poetry: A Critical Edition. New York: Fordham UP, 2008.

Halliday, M.A.K. Spoken and Written Language. Geelong: Deakin UP, 1985.

Handel, Zev. "Towards a Comparative Study of Sinographic Writing Strategies in Korean, Japanese, and Vietnamese." Proceedings of the SCRIPTA 2008, Seoul, Oct. 8-12, $2008,105^{-134 .}$

Hannas, William C. The Writing on the Wall: How Asian Orthography Curbs Creativity. Philadelphia: Pennsylvania UP, 2003.

Hansen, Chad. Language and Logic in Ancient China, Ann Arbor: University of Michigan Press, 1983 .

Hansen, Chad. "Chinese Ideographs and Western Ideas." Journal of Asian Studies 52: 2 (1993), 373-399.

Honey, David. B. Incense at the Altar: Pioneering Sinologists and the Development of Classical Chinese Philology, New Haven: American Oriental Society, 2001.

Kennedy, George A. "Fenollosa, Pound and the Chinese Character." Yale Literary Magazine 126: 5 (1958). Reprinted in Selected Works of George A. Kennedy, ed. Tien-yi Li, New Haven: Far Eastern Publications Yale University. 1964, 443-462. 
Klein, Lucas. "Indic Echoes: Form, Content, and World Literature in Tang Dynasty Regulated Verse." Chinese Literature: Essays, Articles, Reviews 35 (2013), 59-96.

Labov, William \& with Joshua Waletzky. "Narrative Analysis." In Essays on the Verbal and Visual Arts, ed. J. Helm. Seattle: University of Washington Press, 1967, 12-44.

Lurie, David B. "Language, Writing and Disciplinarity in the Critique of the 'Ideographic Myth': Some Proleptical Remarks." Language and Communication 26 (2006), 250269 .

Mair, Victor H. \& Tsu-Lin Mei. "The Sanskrit Origins of Recent Style Prosody." Harvard Journal of Asiatic Studies 51 (1991), 375-470.

McDonald, Edward. "Getting over the Walls of Discourse: 'Character Fetishization' in Chinese Studies.” Journal of Asian Studies 68: 4 (2009), 1189-1213.

McDonald, Edward. "Ideolatry vs Phonolatry? Chinese Characters as Disciplinary Identifier." In Learning Chinese, Turning Chinese: Challenges to Becoming Sinophone in a Globalised World. London, Routledge, 2011, 109-131.

Mungello, David. Curious Land:Jesuit Accommodation and the Origins of Sinology. Honolulu: University of Hawaii Press, 1985.

O'Neill, Timothy. “Xu Shen's Scholarly Agenda: A New Interpretation of the Postface of the Shuowen jiezi." Journal of the American Oriental Society 133: 3 (2013), 413-440.

Porter, David. Ideographia: The Chinese Cipher in Early Modern Europe. Stanford CA: Stanford UP, 2001.

Rosemont, Henry Jr. "On Representing Abstractions in Archaic Chinese." Philosophy East and West, 24: 1 (1974), 71-88.

Saussure, Ferdinand de. Cours de linguistique générale. Trans. Wade Baskin. Course in General Linguistics. New York: McGraw-Hill, 1916/1957.

Saussure, Ferdinand de. Écrits de linguistique générale. Trans. Carol Sanders \& Matthew Pires, Writings in General Linguistics. Oxford: Oxford UP, 2006.

Shen, Xiaolong 申小龍. Zhongguo wenhuayuyanxue 中國文化語言學 (Chinese Cultural Linguistics). Changchun: Jilin Education Press, 1990.

Vihan, Jan. "Language, Likeness, and the Han Phenomenon of Convergence." Diss. Harvard University, 2012.

Yip, Wai-lim. Ezra Pound's Cathay. Princeton: Princeton up, 1969

Zhan, Xuzuo詹緒左 \& Zhu Liangzhi 朱良志. Zuowei wenhua quezheng de hanzi 作為 文化確證的漢字 (Graphology and Culture:How Chinese Characters Verify Beliefs and Ideologies.) Journal of Oriental Studies 33: 1 (1995), 76-94.

Zhao Heping. "Wen Xin Diao Long: An Early Chinese Rhetoric of Written Discourse." Diss. Purdue University, 1990.

Zuo, Min'an 左民安. Xishuo hanzi: 10oo ge hanzi de qiyuan yu yanbian 細說漢字: 1000個 漢字的起源與演變 (Chinese Characters in Detail: The Origins and Evolution of 1,00o Chinese Characters). Beijing: Zhongxin chubanshe, 2005. 